\title{
Building a Viable Weight Management Program in a Patient- Centered Medical Home
}

Stephanie B. Wilhoit-Reeves, MDiv, MSW; Laurel A.G. Sisler, MSW; Shannon E. Aymes, MD; Shiara M. Ortiz-Pujols, MD, MPH; Deborah S. Porterfield, MD, MPH; Adam O. Goldstein, MD, MPH

BACKGROUND AND OBJECTIVES: The growing prevalence of obesity in the United States and globally highlights the need for innovative strategies to provide obesity treatment in primary care settings. This report describes and evaluates the Weight Management Program (WMP), an interprofessional program in an academic family medicine clinic delivering intensive behavioral therapy (IBT) following evidenced-based guidelines.

METHODS: We extracted WMP participant health data from the electronic health record and evaluated retrospectively. Eligible participants completed at least four WMP visits and had a baseline weight, blood pressure, and hemoglobin $A_{1 c}\left(H b A_{1 c}\right)$ recorded within 1 year prior to their first visit. Paired $t$ tests were used to assess changes in, weight, $\mathrm{HbA}_{1 \mathrm{c}}$ and systolic and diastolic blood pressures from baseline.

RESULTS: WMP counseled 673 patients over 3,895 visits from September 2015 to June 2019. Of these, 186 met eligibility criteria (at least four visits), with a median of eight visits (mean=11.3, SD=8.1). Participants saw an average weight decrease during program participation of 9.7 Ibs $(P<.001)$, an average decrease in $\mathrm{HbA}_{1 \mathrm{c}}$ of 0.2 points $(P=.004)$, and an average blood pressure reduction of $2.8 \mathrm{mmHg}$ systolic $(P=.002)$ and $1.9 \mathrm{mmHg}$ diastolic $(P=.03)$. One-third of participants $(n=60)$ achieved clinically significant weight loss $(>5 \%)$ at 18 months. The program has become financially sustainable through billing for preventive counseling services and a \$125 out-of-pocket enrollment fee.

CONCLUSIONS: WMP provides one model for primary care practices to develop a financially sustainable and evidence-based behavioral therapy weight management program for their patients with obesity. Future work will include assessment of longer-term program benefits, quality metrics, and health care costs.

(Fam Med. 2020;52(6):427-31.)

doi: 10.22454/FamMed.2020.418736

0 besity is a major cause of preventable death and disability, with increasing prevalence globally. Over $30 \%$ of US adults meet criteria for obesity (body mass index $[\mathrm{BMI}] \geq 30 \mathrm{~kg} / \mathrm{m}^{2}$ ), increasing their risk of cancer, heart disease, diabetes, and arthritis. ${ }^{1-2}$ Effective , high-intensity strateg behavioral therapy (IBT) defined as greater than 12 sessions focused on a reduced calorie diet, increased physical activity, and behavioral strategies to improve adherence. ${ }^{4-5}$ Guidance is limited on how to translate these findings into real-world settings with practical challenges such as providers' scant time and training, causing few to deliver IBT as recommended by the US Preventive Services Task Force (USPSTF) and the Centers for Medicare and Medicaid Services (CMS). ${ }^{6-11}$ Confronted with this challenge, an interprofessional group developed the Weight Management Program (WMP), an evidence-based, financially sustainable program that is scalable to academic primary care settings. This report outlines its inception, components, and initial clinical and financial outcomes.

\section{Methods}

Setting

WMP is located within the family medicine center (FMC) at the University of North Carolina at Chapel Hill. The center completes over 66,000 patient visits annually. This setting allows for an interprofessional team of clinical social workers, physicians, dieticians, and learners to deliver IBT to patients with obesity. address all its dimensions. ${ }^{3}$ Primary care providers are ideally suited to manage this chronic disease. Two large trials report clinically significant weight loss in primary care settings stemming from high-intensity
From the Department of Family Medicine, University of North Carolina, Chapel Hill, North Carolina. 


\section{Intervention}

The FMC has operated a Tobacco Treatment Program since 2007. Given the parallel motivational and behavioral changes required to stop tobacco use and maintain weight loss, staff surveyed FMC providers regarding their desire for a similar program to treat obesity. Results revealed an unmet need, spurring a WMP pilot in 2015, which began with one clinical social worker offering four counseling hours per week of IBT to a quarter of FMC patients with obesity. The program expanded to all FMC patients in 2016 and to outside and self-referred patients in 2017 (Table 1). This report gives outcomes throughout the program's evolution.

WMP's structure is based on USPTF and CMS guidelines, offering 26 IBT sessions via group and individual counseling over 1 year (Figure 1). Participants first complete a group orientation where they learn WMP's guiding principles, nutrition guidelines (Harvard's Healthy Eating Plate) ${ }^{12}$ and set SMART (specific, measureable, action-oriented, realistic and time-bound) goals to promote weight loss. WMP's guiding principles are: (1) sustainable change; (2) 5\%-10\% weight loss; (3) setting goals and taking positive health actions; and (4) self-care.

After orientation, participants choose to initiate individual and/or group counseling. In 30-minute individual sessions, clinicians engage patients using motivational interviewing, help them set SMART goals, and employ cognitive behavioral therapy and mindfulness techniques focused on helping patients maintain clinically significant weight loss (at least $5 \%$ from baseline). ${ }^{13}$

Sixty-minute group sessions, based on the Diabetes Prevention Program's "Prevent T2" curriculum occur twice per month. ${ }^{14}$ The curriculum is repeated allowing for rolling admission.

WMP also offers monthly maintenance group visits beyond the initial year. These groups do not follow a specific curriculum but focus on longterm behavior change strategies.

Current paid staff includes 20 counseling hours per week by clinical social workers. WMP has also integrated preventive medicine and family medicine residents and graduate students into the treatment team. Residents and students work alongside experienced clinicians before working independently. Ongoing education includes biweekly case consultations, guest speakers, and journal article review. WMP clinicians refer patients to registered dieticians, obesity medicine specialists, and bariatric surgeons when appropriate.

\section{Evaluation Methods}

We extracted participant health data from the electronic health record and evaluated retrospectively. Analysis was limited to FMC patients with multiple weight, blood pressure, and hemoglobin $\mathrm{A}_{1 \mathrm{c}}\left(\mathrm{HbA}_{1 \mathrm{c}}\right)$ values documented over time. Similar to other studies showing sustained program commitment, eligibility for evaluation required completion of at least four visits, though the mean number of sessions completed (11.3, $\mathrm{SD}=8.1$ ) was closer to the 12 session cutoff for
IBT. ${ }^{15}$ Changes in weight and systolic and diastolic blood pressures were determined by comparing the last value measured within 18 months to baseline. Changes in $\mathrm{HbA}_{1 c}$, typically an annual measure, were determined by comparing the last value measured within 24 months to baseline. We used paired $t$ tests to assess changes in $\mathrm{HbA}_{1 \mathrm{c}}$, weight, and systolic and diastolic blood pressures from baseline (Figure 1).

The University of North Carolina's Institutional Review Board approved this study (\#18-0358).

\section{Results}

From September 2015 to June 2019, WMP served 673 individuals over 3,895 visits (Table 2). Participants' mean starting weight was $248 \mathrm{lbs}$ $(\mathrm{SD}=58.3)$ and average weight loss was $6.12 \mathrm{lbs}(\mathrm{SD}=21.7)$, or $2.4 \%$ ( $\mathrm{SD}=7.7 \%)$. Of the patients served, 186 met inclusion criteria for evaluation with at least four visits and a baseline weight, blood pressure, and $\mathrm{HbA}_{1 c}$ recorded. Participants completed an average of 11.3 visits (median=8, $\mathrm{SD}=8.1$ ) with $16 \%$ participating in group sessions. Average $\mathrm{HbA}_{1 \mathrm{c}}$ decreased significantly (6.7 to $6.5, \mathrm{P}=.004)$. Participants' systolic and diastolic blood pressures showed significant improvement (mean difference $2.8 \mathrm{mmHg}, P=.002$, and 1.9 , $P=.03$, respectively). Participants experienced a significant reduction in weight ( $9.7 \mathrm{lbs}, P<.001)$. See Table 3 for detailed results.

Financial sustainability through billing receipts was not possible with preventive counseling CPT codes exclusively (Figure 2). WMP was

Table 1: Weight Management Program Growth, 2015-2019

\begin{tabular}{|l|c|c|c|c|c|}
\hline \multicolumn{1}{|c|}{ Year } & $\begin{array}{c}\text { Patient Visits per } \\
\text { Month } \\
\text { Mean (SD) }\end{array}$ & $\begin{array}{c}\text { Total Patients } \\
\text { Served }\end{array}$ & $\begin{array}{c}\text { MSW Clinical } \\
\text { FTE }\end{array}$ & $\begin{array}{c}\text { Total MSW } \\
\text { Interns }\end{array}$ & $\begin{array}{c}\text { Total Preventive } \\
\text { Medicine Residents }\end{array}$ \\
\hline September-December 2015 & $23.5(10.5)$ & 34 & 0.2 & 0 & 0 \\
\hline 2016 & $52.2(27.6)$ & 141 & 0.4 & 1 & 1 \\
\hline 2017 & $104.2(15.0)$ & 290 & 0.5 & 1.5 & 1 \\
\hline 2018 & $98(8.7)$ & 246 & 0.5 & 2 & 2 \\
\hline January-June 2019 & $124.7(13.6)$ & 190 & 0.5 & 2 & 2 \\
\hline
\end{tabular}


initially subsidized by institutional funding for tobacco treatment programs. Consequently, WMP added an out-of-pocket $\$ 125$ enrollment fee, which nearly covers all expenses when combined with receipts. Paid

Figure 1: Statistical Analysis Flowchart

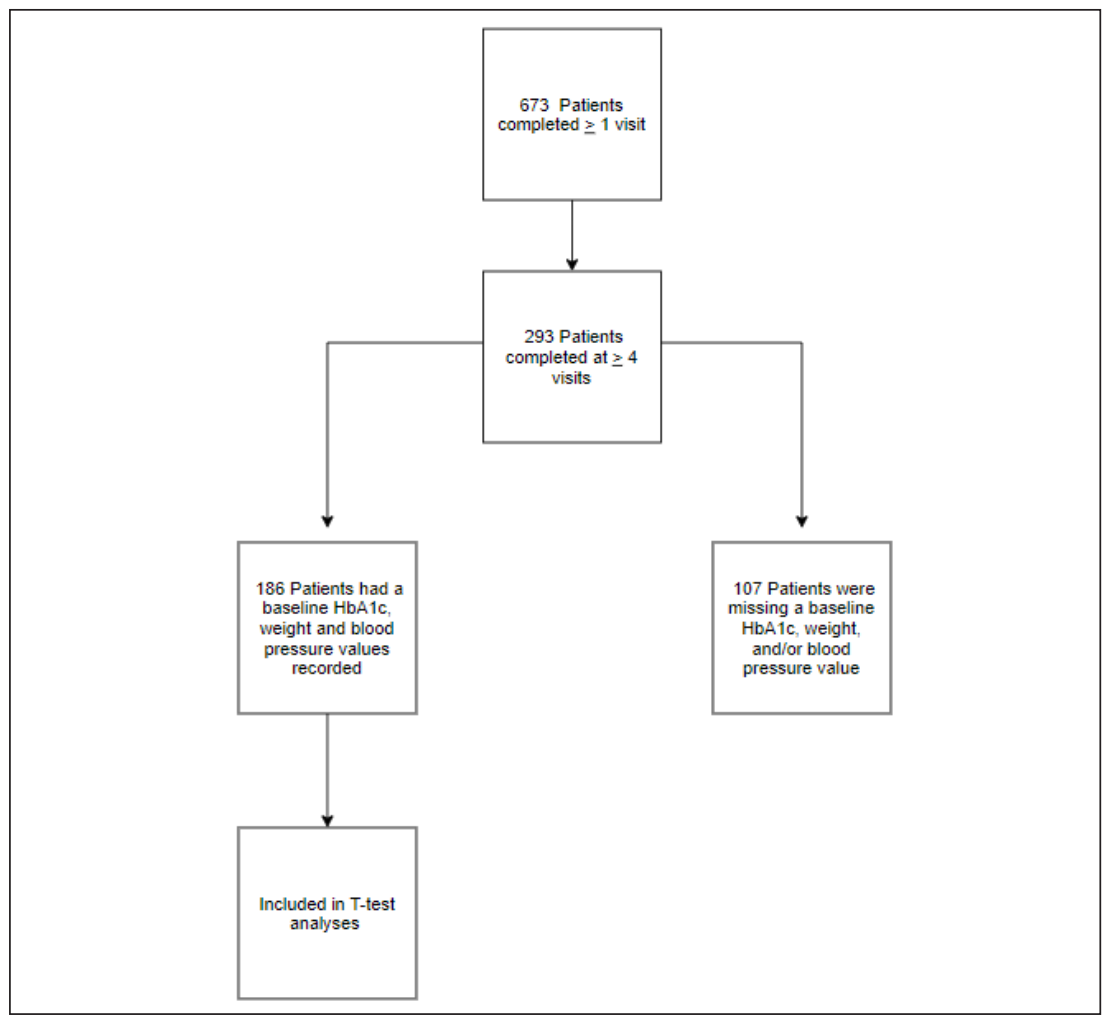

expenses are 20 counseling hours per week by clinical social workers. Inkind expenses include medical director oversight, counseling and office space, and learner clinic time.

\section{Discussion}

Obesity is the second-leading cause of preventable death globally. ${ }^{16}$ Primary care providers are well-positioned to treat obesity, but lack time to help patients achieve lasting behavior change. WMP highlights the role nonphysician providers have in comprehensive, affordable, and evidence-based obesity treatment. It provides a model for building weight management into the operations of an academic family medicine department, which can draw from a diverse panel of ancillary providers to extend care delivery, promote interprofessional collaboration, and enhance training. The program appears to demonstrate that IBT sessions are associated with clinically significant weight loss and improvements in $\mathrm{HbA}_{1 \mathrm{c}}$ and blood pressure.

This study has several limitations. Participants were mostly female, making it difficult to discern gender differences. Only one-half of patients completed at least four_visits, showing additional efforts are needed to retain participants. Potential factors influencing retention include cost, insurance coverage variability, recommended visit frequency, and the program's focus on sustainable change over rapid weight loss,

Table 2: Demographics ( $n=673)$

\begin{tabular}{|l|l|c|c|}
\hline \multicolumn{2}{|c|}{ Characteristic } & $\%(\mathbf{n})$ & $\begin{array}{c}\text { Patient Visits } \\
\text { Mean (SD) }\end{array}$ \\
\hline \multirow{4}{*}{ Race } & White/Caucasian & $47.3(318)$ & $6.8(7.8)$ \\
\cline { 2 - 4 } & Black/African American & $43.5(293)$ & $5.1(6.5)$ \\
\cline { 2 - 4 } & Other & $9.2(62)$ & $3.8(5.2)$ \\
\hline \multirow{4}{*}{ Ethnicity } & Non-Latino/Hispanic & $92.0(619)$ & \\
\cline { 2 - 4 } & Latino/Hispanic & $5.0(34)$ & \\
\cline { 2 - 4 } & Other & $3.0(20)$ & $5.7(6.9)$ \\
\hline \multirow{5}{*}{ Biological sex } & Female & $77.9(524)$ & $6.2(7.8)$ \\
\cline { 2 - 4 } & Male & $22.1(149)$ & $6.2(7.5)$ \\
\hline & Hypertension & $55(372)$ & $5.8(8.2)$ \\
\cline { 2 - 4 } & Depression & $28(187)$ & $5.5(6.6)$ \\
\cline { 2 - 4 } & Diabetes mellitus, type 2 & $26(176)$ & $6.9(7.5)$ \\
\cline { 2 - 4 } & Obstructive sleep apnea & $23(156)$ & $6.8(7.7)$ \\
\cline { 2 - 4 } & Osteoarthritis & $22(147)$ & $8.0(10.2)$ \\
\cline { 2 - 4 } & Polycystic ovarian syndrome & $5(33)$ & \\
\hline
\end{tabular}


Table 3: Change in Health Values From Baseline to Follow-up of Participants in UNC Weight Management Program, a Primary Care-based Weight Management Program*

\begin{tabular}{|c|c|c|c|}
\hline & $\begin{array}{c}\text { Total } \\
\mathrm{n}=\mathbf{1 8 6} \\
\text { Mean (SD or } 95 \% \mathrm{Cl})\end{array}$ & $\begin{array}{c}\text { Male } \\
\mathrm{n}=38(20.43 \%) \\
\text { Mean (SD or } 95 \% \mathrm{Cl})\end{array}$ & $\begin{array}{c}\text { Female } \\
\mathrm{n}=\mathbf{1 4 8}(\mathbf{7 9 . 5 7 \% )} \\
\text { Mean (SD or } 95 \% \mathrm{Cl})\end{array}$ \\
\hline Pre $\mathrm{HbA}_{1 \mathrm{c}}(\%)$ & $6.66(1.45)$ & $6.99(1.75)$ & $6.57(1.38)$ \\
\hline Post $\mathrm{HbA}_{1 \mathrm{c}}(\%)$ & $6.46(1.29)$ & $6.81(1.57)$ & $6.37(1.19)$ \\
\hline Pre-post change in $\mathrm{HbA}_{1 \mathrm{c}}$ & $0.196(0.007-0.385, P=.04)$ & $0.185(-0.428-0.798, P=.53)$ & $0.198(0.009-0.388, P=.04)$ \\
\hline Pre systolic BP (mmHg) & $133.6(15.23)$ & $138.13(16.79)$ & $132.40(14.64)$ \\
\hline Post systolic BP (mmHg) & $130.8(15.95)$ & $134.34(18.72)$ & $129.87(15.11)$ \\
\hline Pre-post change in systolic BP & $2.78(0.45-5.11, P=.02)$ & $3.79(-1.70-9.28, P=.17)$ & $2.52(-0.82-5.122, P=.06)$ \\
\hline Pre diastolic BP (mmHg) & $80.96(10.23)$ & $83.08(9.22)$ & $80.42(10.43)$ \\
\hline Post diastolic BP (mmHg) & $79.03(10.69)$ & $81.16(10.11)$ & $78.48(10.80)$ \\
\hline Pre-post change in diastolic BP & $1.94(0.214-3.66, P=.03)$ & $1.92(-0.95-4.79, P=.18)$ & $1.94(-0.11-3.99, P=.06)$ \\
\hline Pre weight (lbs) & $252.87(55.91)$ & $280.57(50.33)$ & $245.76(55.20)$ \\
\hline Post weight (lbs) & $243.15(56.70)$ & $270.13(53.70)$ & $236.22(55.53)$ \\
\hline Pre-post change in weight & $9.72(6.57-12.87, P<.001)$ & $10.44(1.57-19.31, P=.022)$ & $9.53(6.23-12.84, P<.001)$ \\
\hline$\geq 5 \%$ weight loss & $32.26 \%(\mathrm{n}=60)$ & $26.32 \%(\mathrm{n}=10)$ & $33.78 \%(\mathrm{n}=50)$ \\
\hline$\geq 7 \%$ weight loss & $21.5 \%(\mathrm{n}=40)$ & $18.42 \%(\mathrm{n}=7)$ & $22.3 \%(\mathrm{n}=33)$ \\
\hline$\geq 10 \%$ weight loss & $13.98 \%(\mathrm{n}=26)$ & $10.53 \%(\mathrm{n}=4)$ & $14.86 \%(\mathrm{n}=22)$ \\
\hline
\end{tabular}

* These data exclude $72.4 \%(\mathrm{n}=487)$ of total patients served who either did not complete four sessions or did not have a baseline $\mathrm{HbA}_{1 \mathrm{c}}$ value, within 12 months of their start date, to compare changes.

Figure 2: Financial Sustainability Over Time: Expenses vs Income

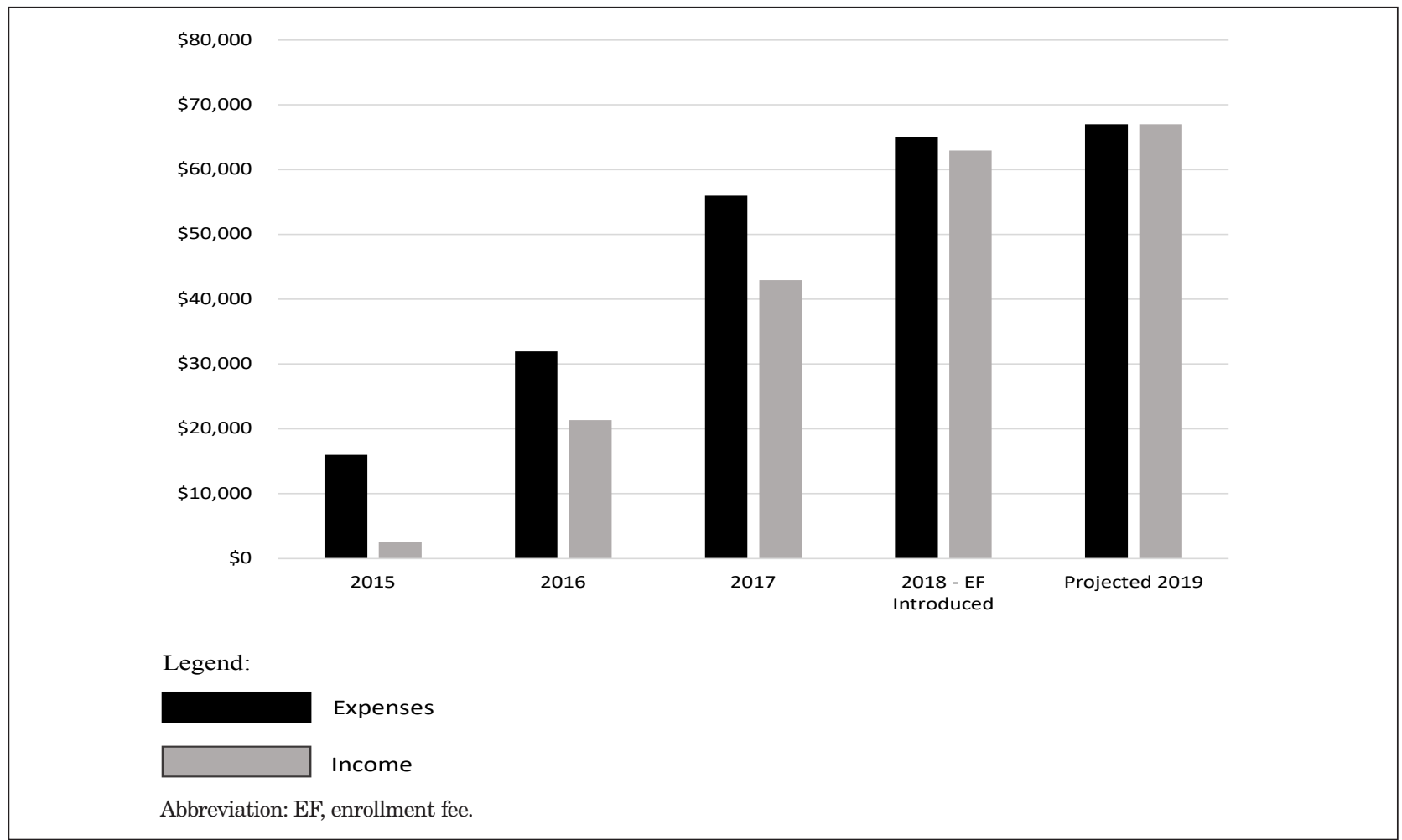


which is not aligned with some patients' goals. While we saw significant changes in $\mathrm{HbA}_{1 \mathrm{c}}$ values, only half of eligible patients had follow-up $\mathrm{HbA}_{1 \mathrm{c}}$ values, which may have limited an ability to detect even larger differences in glucose control. Blood pressure and weight measurement strategies were not standardized as they were obtained by multiple personnel during clinical encounters. Finally, several variables were not measured, such as quality of life indicators.

We learned that existing preventive counseling CPT codes (G0447, 99402-99404, 99412) are insufficient to achieve financial sustainability. Instead, WMP reached sustainability by including an out-of-pocket enrollment fee and in-kind institutional resources. The enrollment fee likely limits low-income patient participation. WMP investigated a sliding scale fee structure and scholarships, however institutional policies have not permitted these solutions. Leadership continues to explore strategies to increase access.

This real-world study of a weight management program within a busy academic practice highlights the applicability for other primary care practices. WMP is undertaking quality improvement efforts to increase retention, including the use of telemedicine. Broader adoption of such evidence-based models is critical in treating obesity, particularly as the US health care system transitions toward a value-based payment model wherein health care systems are paid a set amount per patient to deliver quality care. ${ }^{17}$ Under this new model, it is vital to assess WMP's impact on overall cost per patient and quality metrics related to weight loss, blood pressure, and $\mathrm{HbA}_{1 \mathrm{c}}$.

ACKNOWLEDGMENTS: The authors thank the many people who have helped build WMP through data reporting, IRB approval, and collaborative patient care. This list includes, but is not limited to: Nathan Brunson, Christopher Burner, Allegra Burton, Patricia Cary, Meredith Duke, Tim Farrell, Laura Farris,
Kevin Greats, Laura Higginbotham, Angela Lipscomb-Hudson, Sriram Machineni, Lana Nasrallah, Seyi Olusina, Christine Peat, Kylie Piper, Avril Rowerdink, Abby Sepanski, Phlip Sloane, Susannah Southern, Sarah Sterling, Ryan Talbert, Kevin Tate, Shavonda Thomas and Robert White.

The authors appreciate the UNC Department of Health Behavior in the Gillings School of Global Public Health for their two capstone projects, which were integral to the foundation of the program. Finally the authors are grateful for the ongoing support and teamwork of all the faculty, residents and staff of the UNC Family Medicine Center, Chapel Hill, North Carolina.

RELATED PRESENTATIONS: Portions of this report were included in the following presentations:

1. Ortiz-Pujols S, Wilhoit-Reeves S Sisler L, Burner C, Kaysin A, Goldstein AO. Lessons learned from implementing a weight management program in a patientcentered medical home based on USPSTF recommendations. Presentation at the 2018 Society of Teachers of Family Medicine Annual Spring Conference in Washington, DC

2. Ortiz-Pujols S, Wilhoit-Reeves S, Sisler L, Porterfield D, Goldstein AO. Is it possible to have a financially viable, evidence-based weight management program in a patient centered medical home? Presented at the 2018 ObesityWeek Annual Conference in Nashville, TN.

3. Sisler L, Costa J. Promoting sustainable weight loss: a model for weight management in primary care. Presented at the 2019 Society of Teachers of Family Medicine Annual Spring Conference in Toronto, Ontario, Canada.

CORRESPONDING AUTHOR: Address correspondence to Ms Stephanie Wilhoit-Reeves, 590 Manning Drive, Campus Box 7595, Chapel Hill, NC 275997595. 984-974-4988. Fax: 919-966-6125. stephanie_wilhoit-reeves@med.unc.edu.

\section{References}

1. Hales CM, Carroll MD, Fryar CD, Ogden CL Prevalence of obesity among adults and youth: United States, 2015-2016. NCHS Data Brief. 2017;(288):1-8

2. US Department of Health and Human Services; National Institutes of Health; National Heart Lung and Blood Institute. Managing overweight and obesity in adults: systematic evidence. Review from the Obesity Expert Panel. 2013. https://www.nhlbi.nih.gov/sites/default/ files/media/docs/obesity-evidence-review.pdf. Accessed June 5, 2019.

3. Tronieri JS, Wadden TA, Chao AM, Tsai AG Primary care interventions for obesity: review of the evidence. Curr Obes Rep. 2019;8(2):128 136.

4. Appel LJ, Clark JM, Yeh HC, et al. Comparative effectiveness of weight-loss interventions in clinical practice. N Engl J Med. 2011;365(21):1959-1968.
5. Wadden TA, Volger S, Sarwer DB, et al. A two-year randomized trial of obesity treatment in primary care practice. N Engl J Med. 2011;365(21):1969-1979.

6. Adams KM, Butsch WS, Kohlmeier M. The state of nutrition education at US medical schools. J Biomed Educ. 2015;2015:1-7.

7. Chung M, van Buul VJ, Wilms E, Nellessen N, Brouns FJPH. Nutrition education in European medical schools: results of an international survey. Eur J Clin Nutr. 2014;68(7):844-846.

8. Mattar A, Carlston D, Sariol G, et al. The prevalence of obesity documentation in Primary Care Electronic Medical Records. Are we acknowledging the problem? Appl Clin Inform. 2017;8(1):67-79.

9. Waring ME, Roberts MB, Parker DR, Eaton CB. Documentation and management of overweight and obesity in primary care. J Am Board Fam Med. 2009;22(5):544-552.

10. Centers for Medicare and Medicaid Services; Jacques L, Jensen TS, Schafer J, McClain S, Chin J. Decision Memo for Intensive Behavioral Therapy for Obesity (CAG-00423N). https:// go.cms.gov/2imiyuH. Published November 29, 2011. Accessed June 5, 2019.

11. US Preventive Services Task Force.Final recommendation statement: obesity in adults: screening and management. 2016. https://www. guidelinecentral.com/summaries/final-recommendation-statement-obesity-in-children-andadolescents-screening/\#section-society. Accessed March 10, 2020

12. Willett WC, Skerrett PJ. Eat, drink, and be healthy: The Harvard Medical School guide to healthy eating. New York: Simon \& Schuster; 2001.

13. Thomas PR; National Academy of Sciences, Institute of Medicine. Weighing the Options: Criteria for Evaluating Weight-Management Programs. Washington, DC: National Academy Press; 1995.

14. Knowler WC, Fowler SE, Hamman RF, et al; Diabetes Prevention Program Research Group. 10-year follow-up of diabetes incidence and weight loss in the Diabetes Prevention Program Outcomes Study. Lancet. 2009;374(9702):1677-1686

15. Jiandani D, Wharton S, Rotondi MA, Ardern CI, Kuk JL. Predictors of early attrition and successful weight loss in patients attending an obesity management program. BMC Obes. 2016;3(14):14.

16. Blumenthal D, Seervai S. Rising Obesity in the United States Is a Public Health Crisis, To the Point. The Commonwealth Fund. https://www. commonwealthfund.org/blog/2018/rising-obesity-united-states-public-health-crisis. Published April 23, 2018. Accessed March 10, 2020.

17. Henkel RJ, Maryland PA. The Risks and Rewards of Value-Based Reimbursement. Front Health Serv Manage. 2015;32(2):3-16. 